\title{
Response of a complex ecosystem model of the northern Adriatic Sea to a regional climate change scenario
}

\author{
M. Vichi ${ }^{1, *}$, W. May ${ }^{2}$, A. Navarra1 \\ ${ }^{1}$ National Institute for Geophysics and Volcanology (INGV), Via Donato Creti 12, 40128 Bologna, Italy \\ ${ }^{2}$ Danish Meteorological Institute (DMI), Lyngbyvej 100, 2100 Copenhagen, Denmark
}

\begin{abstract}
This paper investigates the impact of a regional climate change scenario on an ecosystem model of the northern Adriatic Sea. The study was performed by applying a biogeochemical biomass-based ecosystem model (ERSEM: European Regional Seas Ecosystem Model) coupled with a 1-dimensional version of a commonly used hydrodynamical model (POM: Princeton Ocean Model). The model response was studied by performing 2 simulations: one with atmospheric forcing functions for present-day climate conditions ('Control', 1970-1999), and one for the future climate after a doubling of the $\mathrm{CO}_{2}$ concentration ('Scenario', 2060-2089). Time-series of meteorological forcing functions were obtained from a greenhouse gas experiment with the high-resolution version of the ECHAM4 atmospheric general circulation model with a horizontal resolution of about $100 \mathrm{~km}$. Present-day simulation results were compared to the available historical observations and showed a satisfactory agreement with the main seasonal cycles of hydrodynamical variables and nutrients in the limits of the 1-dimensional representation. Under the Scenario conditions, the model predicted an overall enhancement of the water-column stratification on an annual basis, with stronger intensification during the summer periods. The diffusion of oxygen and nutrients between surface and bottom layers is reduced, and the transfer of organic matter through the food web is shifted towards the smaller components of the microbial web. The model gives indications of an increase in the specific phytoplankton uptake rates of inorganic carbon in the Scenario, but the photosynthesized carbon ends up in the DOC pool because of the reduced supply of nutrients. The mean annual concentration of DOC is thus higher in the Scenario, with possible negative consequences on the water quality. Additional experiments show that the response of primary producers is not directly linked to the increase in ambient temperature. The structure of the food web modulates the interaction of phytoplankton with the abiotic conditions. The results give indications of a possible non-linear response of the biogeochemical cycles to the climate change warming scenario and confirm the feasibility of using the downscaling technique to couple large-scale climate models with comprehensive regional ecosystem models.
\end{abstract}

KEY WORDS: Marine biogeochemical model $\cdot$ Shelf sea ecosystem $\cdot$ Northern Adriatic $\cdot$ Regional climate change $\cdot$ ERSEM

\section{INTRODUCTION}

The use of numerical models for predicting the impact of anticipated climate change has been constantly fostered in recent international forums. Indeed, during the last decade, there has been a remarkable improvement of the models used for the quantitative evaluation of the consequences of global warming on the coupled system of the atmosphere, ocean and biosphere. Together with the scientific research on global climate, there is an increasing number of studies on the local effects of large-scale changes. It is expected that 
some areas will show a higher sensitivity, leading to regional or local amplification of the global change signal, including the risk of coastal flooding and other overall modifications of the marine ecosystem (Ingram et al. 1996, Nicholls \& Hoozemans 1996, Nicholls et al. 1999, Plag \& Tsimplis 1999, Simas et al. 2001). The estimation of such local effects, especially on the dynamics of marine biotic components in shelf seas, is still uncertain. When dealing with natural biogeochemical processes we need to take into account many interconnected feedback mechanisms and adapting factors. In the case of coastal marine systems, the interaction between the large-scale global signal and the local short-term variability of the forcing functions is even much stronger than in open-ocean ecosystems or in terrestrial ecosystems (Steele 1985, Mann 1988). In this conditions, it is difficult to assess what the long-term deterministic predictability of the system behaviour would be. Most of the uncertainties are related to the approach used to describe the biogeochemical processes (Sarmiento et al. 1998). Therefore, we consider it important to set up exploratory experiments in selected areas, in order to test how a complex physiological model of the marine ecosystem responds to climate change scenarios of global warming.

There have been several recent studies dealing with the effect of environmental warming on ecosystem functioning (Bhaud et al. 1995, Hughes 2000). It is possible to hypothesize 2 main effects on marine ecosystems owing to an increase in ambient temperature. The first direct effect is related to changes in the physiological response of organisms. In general, there is a differential enhancement of both the production and respiration rates that changes the ecological dominance of some species at the expense of others with consequences on the biodiversity (Nike Bianchi \& Morri 2000). Other indirect effects are due to the interaction of biology with hydrodynamics. The modification of horizontal and vertical transports is expected to have a large impact on the availability of external and benthic-regenerated nutrients and more generally on the trophic structure of shallow-sea ecosystems. This could lead to the occurrence of dystrophic phenomena, with possible negative effects on the water quality of the basin. The first effect is difficult to assess by means of the present mechanistic ecosystem models, in which the food web has a fixed structure. In fact, this approach does not allow the introduction of new species according to the availability of new ecological niches. The second one can, on the other hand, partially be addressed with a state-of-the-art coupled physical/biogeochemical ecosystem model.

The aim of this study is to analyze how an ecosystem model simulating the seasonal behaviour of a coastal ecosystem responds to a climate change scenario

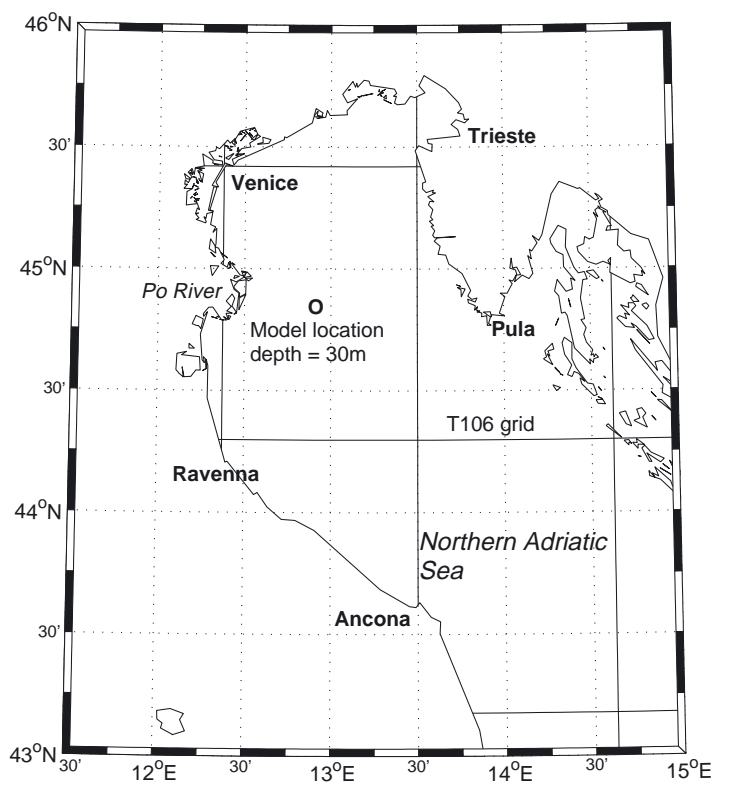

Fig. 1. Idealized model location. The solid line grid represents the T106 grid where the AGCM (atmospheric general circulation model) forcing data are known

involving an increase in ambient temperature. We have focused this analysis on the dynamics of the shallow northern Adriatic Sea (NAD, Fig. 1).

The NAD is certainly one of the most intensively studied basins in the Mediterranean in recent years. It is a typical shallow eutrophicated basin affected by land-derived inputs. In the world coastal ocean the NAD is an example, as is the Baltic Sea, the North Sea and other enclosed basins such as the Black Sea, of a specific marine ecosystem in dynamical interaction with strong anthropogenic pressure (Melvasalo 2000). Such systems are usually considered in case studies for the analysis of long-term changes in order to evaluate the impact of human activities on highly exploited marine environments (e.g. HELCOM 1990, 1996, Degobbis et al. 2000). The dynamical state of the NAD is determined by the mutual interaction between the general circulation of the basin driven by surfaceexchange fluxes and the inflows of freshwater and nutrients from the land, especially from the Po River on the western Italian coast. Because of its semi-enclosed shape and the shallowness of the basin, it strongly responds to small- and medium-scale meteorological events (as bora and scirocco wind) with marked mesoscale variability of currents. These fluctuations are even more evident in the behaviour of the marine biological components, which show a substantial interannual variability with the aperiodic occurrence of anomalous conditions such as near-bottom anoxia or the formation of mucilages (Justic et al. 1987, Fonda Umani 1996, Azam et al. 1999, Degobbis et al. 1999). 
The research was performed by applying an existing complex ecosystem model which describes the coupled interactions between the physics of the water column and the main functional components of marine biota. The response of this coupled model to changes in atmospheric conditions was studied by performing 2 simulations: one prescribing the atmospheric forcing functions for present-day climate conditions (the 'Control' experiment), and one for the future climate after a doubling of the $\mathrm{CO}_{2}$ concentration with respect to the present-day values (the 'Scenario' experiment). Timeseries of surface-forcing functions were obtained from a timeslice greenhouse gas experiment (Section 2). In order to simplify the approach, the model application was restricted to an analysis of the impact of anticipated climate conditions on the vertical dynamics of the NAD ecosystem. A simulated water column was set up to represent the northern Adriatic shelf area (Section 3); we applied some specific parametrizations to model the main seasonal hydrodynamic and biogeochemical characteristics. Present-day conditions as simulated by the 1-dimensional vertical model (1D-V hereafter) were compared to available historical data sets (Adriatic Biogeochemical Dataset, Zavatarelli et al. 1998) and other published information on the long-term characteristics of the NAD ecosystem (Degobbis et al. 2000).

In this work we particularly focused on the response of phytoplankton dynamics due to changes in the physical structure of the water column. Early modelling works (Vichi et al. 2003) have shown the importance of the onset of stratification for the evolution of the phytoplankton bloom. Since coastal areas are generally more limited by light than by nutrient availability (Legendre \& Rassoulzadegan 1995), we expect that modifications of the mixed layer dynamics owing to an increase in the atmospheric temperature can have major impacts on carbon fluxes. The Control and Scenario experiments were thus compared with each other in order to quantitatively describe the changes in the biology induced by the different physical conditions. A sensitivity experiment on the structure of the ecosystem model was also performed. Finally, some preliminary assessments are drawn, considering the restrictions given by the reduced number of dimensions, the high natural variability of coastal systems and the uncertainties inherent to predictions of future climate.

\section{THE TIME-SLICE APPROACH}

Global coupled climate models generally deal with the large-scale features of the mean climate state of the coupled systems of atmosphere, land, oceans and, more recently, biosphere. Therefore, we cannot explicitly have a detailed representation of the dynamical aspects that characterize the future climate changes in specific regions of interest such as the Mediterranean Basin or, even more regional, the northern Adriatic Sea, from these models. The regional climate is affected by smaller scales than those resolved in global coupled climate models, and one of the approaches currently applied to obtain regional climate information is the dynamical downscaling technique.

The regional meteorological forcing fields used in our study originate from a so-called 'time-slice experiment', where an atmospheric general circulation model (AGCM) with a relatively high spatial resolution is used in conjunction with a lower-resolution coupled climate model. We refer the reader to May \& Roeckner (2001) and May (2001) for a review of the time-slice approach and for further details on the time-slice experiment. Here we review the main aspects of the experiment in order to give an idea of how the regional meteorological forcing fields were produced.

The time-slice experiment was performed with the ECHAM4 AGCM at a high horizontal resolution of about $100 \mathrm{~km}$ (T106 Gaussian grid; Roeckner et al. 1996). Two simulations were performed, each covering a period of $30 \mathrm{yr}$. The first one represents the presentday climate (1970-1999), and the second one represents the future climate after an effective doubling of the $\mathrm{CO}_{2}$ concentration in the atmosphere (2060-2089). During these 2 time-slices, the lower boundary forcing, i.e. monthly mean values of the sea-surface temperatures (SSTs) and of the sea-ice extent and sea-ice thickness, were prescribed as obtained from a climate change simulation with the ECHAM4/OPYC coupled climate model at a low horizontal resolution of about 300 km (T42 Gaussian grid; Roeckner et al. 1999). Further, the temporal evolution of the important greenhouse gases (GHGs) has been prescribed in the same way as in the respective climate change simulation, that is, according to observations until 1990 and according to the IPCC scenario IS92a for the period after 1990 (Houghton et al. 1992). Changes in the aerosol concentrations are not considered in this experiment. A thorough discussion of the changes in the mean climate inferred from the 2 time-slices in the European area can be found in May (2001).

In this study we go one step further in the application of the downscaling technique, forcing the high-resolution $1 \mathrm{D}-\mathrm{V}$ model by time-series of meteorological parameters extracted from the aforementioned time-slice experiment of the high-resolution AGCM. The general structure of the applied procedure is depicted in Fig. 2. The meteorological variables, i.e. air temperature, wind velocity, relative humidity, cloud covering and precipitation, were extracted from the AGCM model results with a $6 \mathrm{~h}$ frequency. They are used as forcing functions in the $1 \mathrm{D}-\mathrm{V}$ physical/biological coupled 


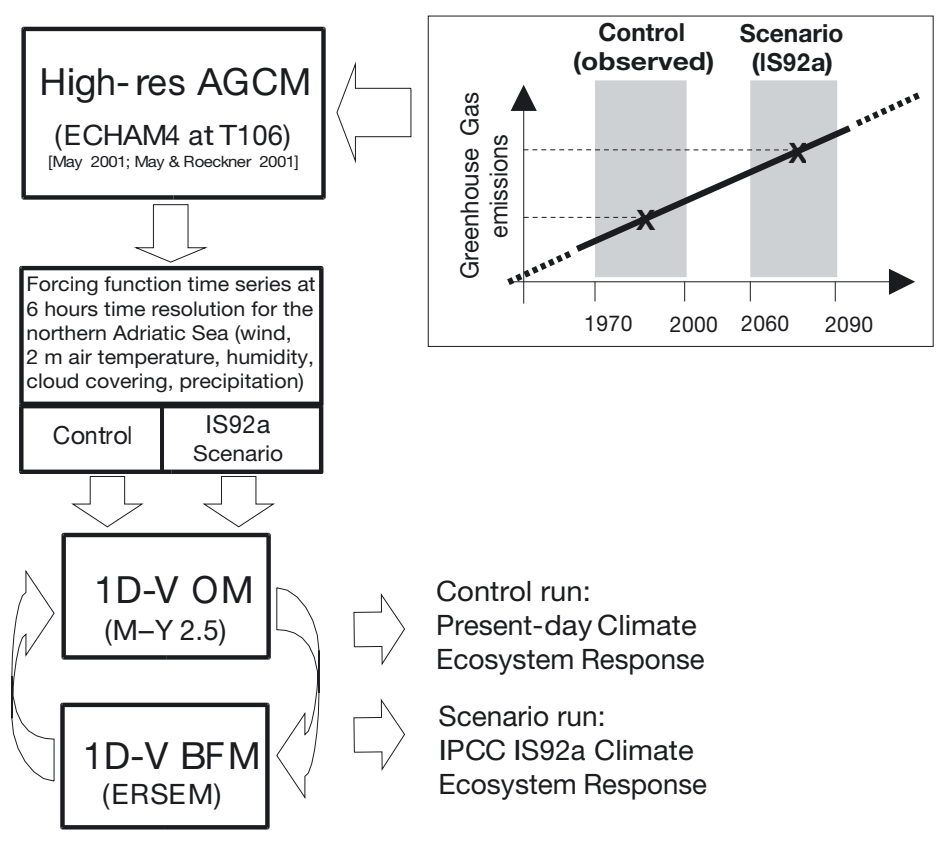

Fig. 2. Scheme of the model coupling and information flow. The timeslice AGCM experiment, forced with observed and anticipated greenhouse gas emissions, generated the surface meteorological forcing functions used in the coupled hydrodynamic/biological model. Two simulations are performed: one describing the present-day ecosystem behaviour, and one simulating the system response to changed atmospheric climate conditions. AGCM: atmospheric general circulation model; 1D-V OM: 1-dimensional vertical ocean model (MellorYamada level 2.5); 1D-V BFM: 1-dimensional vertical biogeochemical flux model (ERSEM: European Regional Seas Ecosystem Model)

model (see also Section 3). Two prognostic simulations of the NAD ecosystem behaviour were generated: one for the present-day climate, and one for the period 2060-2089, which incorporates the atmosphere dynamics induced by the IS92a GHG prescriptions. This procedure allows for an increase in the vertical resolution of the hydrodynamic model, and it makes the coupling with the complex ecosystem model computationally feasible.

\section{MODEL DESCRIPTION}

The coupled physical/biogeochemical model applied in this study (ERSEM: European Regional Seas Ecosystem Model) is the result of long-term collaboration among several European modelling groups, and it has been developed in the framework of EU-funded projects. Various versions of this coupled model have been applied at different locations in the world ocean, showing the generic applicability of its design as an exploratory tool for the understanding and description of the main biogeochemical seasonal cycles (Allen et al. 1998, 1999, Vichi et al. 1998a, b, 2000, 2003, Zava- tarelli et al. 2000, Obernosterer et al. 2001, Vichi 2002).

The physical part of the model consists of a 1-dimensional version of the Princeton Ocean Model (POM; Blumberg \& Mellor 1987), which is essentially the numerical solution of the hydrostatic primitive equations for fluid dynamics, with a second-moment turbulence closure model embedded (Mellor \& Yamada 1982, Galperin et al. 1988). A more detailed description of the model equations for the hydrodynamics is given in Vichi et al. (1998a). The 1D-V version computes the timeevolution of SST, salinity and turbulent diffusivity coefficients for momentum and tracers with time-series of meteorological parameters as forcing functions.

The biogeochemical flux model (BFM) is an extension of the ERSEM model (Baretta et al. 1995, Baretta-Bekker 1995, Baretta-Bekker \& Baretta 1997), fully described in Vichi (2002). The ERSEM model perhaps represents the prototype of a comprehensive biomass-based compartment model of marine ecosystems. It consists of a set of interlinked differential equations describing the main physiological processes of unicellular organisms and (to some extent) metazoans, which are grouped together as functional biomass groups by considering their ecological significance. The set of implemented functional groups and their interactions with each other are represented schematically in Fig. 3. The continuous lines joining the boxes indicate fluxes of organic matter (composed of C, N, P, $\mathrm{Si}_{1}$ in varying dynamical proportion within each functional group); the dashed lines indicate fluxes of inorganic nutrients (in form of nitrate, ammonium, orthophosphate and silicate); and the dotted lines mark the exchange of gases $\left(\mathrm{O}_{2}, \mathrm{CO}_{2}\right.$ and $\left.\mathrm{N}_{2}\right)$ between compartments and dissolved pools both in the pelagic and in the benthic system. Each functional group (e.g. phytoplankton $\mathrm{P}$ or zoobenthos $\mathrm{Y}$ ) is composed of different members representing different size-classes, which share the same functional parametrization but different values of the parameters.

The main characteristics of the model can be summarized as follows:

- Closure of the biogeochemical cycles of the main organic and inorganic components $(\mathrm{C}, \mathrm{N}, \mathrm{P}, \mathrm{Si}, \mathrm{O})$ both in the water column and in the sediments. Functional group biomasses are described with multidimensional vectors carrying the information of the (varying) internal contents of nutrients and carbon.

- Decoupled physiological pathways for carbon assimilation and nutrient uptake in primary producers, in 
order to account for 'luxury consumption' and Droop kinetics (Droop 1973, Baretta-Bekker et al. 1997).

- Parametrization of adaptation to the ambient light for autotrophic components (Ebenhöh et al. 1997).

- Explicit parametrization of the microbial loop with distinction of POM and DOM quality for bacteria utilization (Baretta-Bekker et al. 1997, Vichi et al. 2003).

- Parametrized resolution of early diagenetic pro- cesses in the sediments and implementation of the nutrient buffering capacity in the sediments (Ruardij \& Van Raaphorst 1995).

The parameter choices for the current implementation were derived from a comparative analysis with the Baltic model (Vichi 2000, 2002) — having some similarities especially with regard to the trophic state - and previous applications in the NAD (Vichi et al. 1998a, b, 2003).
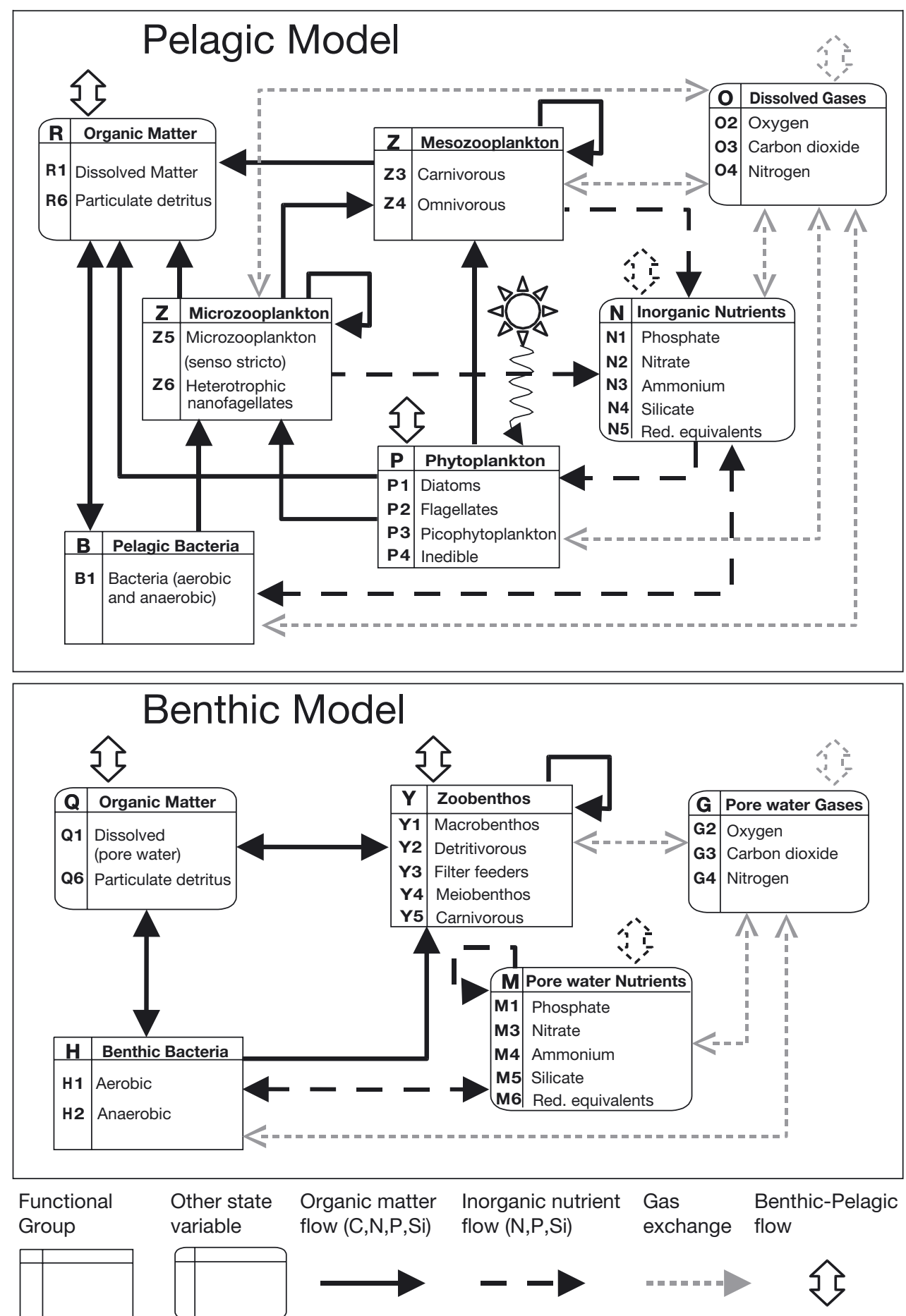

Other state variable

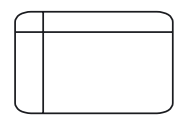

Organic matter flow (C,N,P,Si)
Inorganic nutrient Gas flow (N,P,Si) exchang

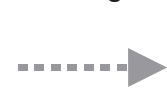

Benthic-Pelagic

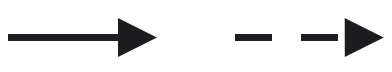

flow

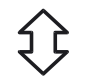

Fig. 3. Scheme of the comprehensive ecosystem model ERSEM. Square boxes represent functional groups defined in terms of their $C_{\text {, }}$ N, P, Si content. Continuous arrows indicate fluxes of carbon and inorganic nutrients, dashed arrows the fluxes of inorganic nutrients $\left(\mathrm{N}, \mathrm{P}_{\text {, }}\right.$ Si) alone and dotted arrows the gas exchange of $\mathrm{O}_{2}, \mathrm{~N}_{2}$ and $\mathrm{CO}_{2}$. Small double arrows above boxes indicate fluxes between the benthic and the pelagic compartments of the model system. Modified and updated from Baretta et al. (1995) 


\section{MODEL IMPLEMENTATION}

The 1D-V model was ideally located in the centre of the NAD, as shown in Fig. 1. It is meant to represent an average behaviour of the whole shallow northern Adriatic. The water column has a depth of $30 \mathrm{~m}$ (average depth of the NAD) and was divided into 40 levels with a logarithmically increasing thickness from the surface and bottom boundaries to the centre. The solid-line grid drawn on the map represents the T106 grid where the AGCM forcing data are known. The average values of the 4 sea-points surrounding the chosen location were used to derive the meteorological time-series. Surface boundary conditions for momentum and heat were interactively computed by means of empirical bulk formulae specifically tuned for the Mediterranean Basin (Castellari et al. 1998, Maggiore et al. 1998, Zavatarelli et al. 2002). Solar radiation at the top of the atmosphere is derived using the astronomical parametrization by Dobson \& Smith (1988) and corrected for cloud cover by using the $6 \mathrm{~h}$ model data from the AGCM. The resulting radiative heat at the surface penetrates through the water column following a parametrized partitioning between infrared and visible radiation, taking into account the attenuation of suspended organic and inorganic particles (see Vichi et al. 2003 for more details).

The solution of the hydrodynamic and biogeochemical equations requires the specification of boundary conditions for all model state variables. In particular, it is necessary to specify the closure of the freshwater and nutrient inputs mainly due to the Po River. Monthly mean values of observed sea-surface salinity from the ABCD (Adriatic BiogeoChemical Dataset) (Zavatarelli et al. 1998) were used to compute the salt flux at the sea surface. The salinity profile was also relaxed to a climatological profile with the procedure described in Vichi et al. (2003) in order to parametrize the horizontal advection of salt waters and maintain the long-term structure of the water column. Since there are no reliable prediction of freshwater runoff changes for the Scenario experiment, we chose to drive both the Control and the Scenario simulations with the same forcing function time-series. Possible consequences on model results are critically analyzed in Sections 4 and 5. A similar approach was used to prescribe surface boundary conditions for nutrients. In this case, surface concentrations are usually associated with the loads carried by the rivers, and we applied a relaxation to seasonal mean values from the ABCD (there are not enough observations available in order to evaluate monthly mean values as done for salinity). The same time-series is used in both the Control and Scenario runs with a relaxation time of $2 \mathrm{~d}$. The estimation of future nutrient loads as derived from changes in the river runoffs is even more difficult than estimating the river runoff itself, because the relationships between nutrient loads and freshwater inflows are non-linear. The available model projections for the Po River are mainly based on linear models (de Wit \& Bendoricchio 2001). Results suggest that without any change in the agriculture, the expected changes in 2015-2020 are nil for nitrogen loads and a small increase (8\% with respect to 1990-1995) for phosphorus. Due to the high uncertainties in future agricultural policies, we have decided to focus on the effect of the meteorological forcing functions only, leaving the assessment of the impact of changed river input conditions to future studies when more reliable scenarios will be available.

Another minor assumption is that the concentration of atmospheric GHGs (especially $\mathrm{CO}_{2}$ ) is not used as a forcing function for the $1 \mathrm{D}-\mathrm{V}$ model. Therefore, the atmospheric inorganic carbon pool does not directly affect the corresponding biogeochemical cycle implemented in the model, but enters indirectly in the physical forcing functions derived from the climate change simulation. Dissolved inorganic carbon in the oceans is 50 times that of the atmosphere (Falkowski et al. 2000) and, for the sake of simplicity, we assumed the $\mathrm{CO}_{2}$ pool in the BFM to be a never-limiting infinite source (as well as sink) for biology. In this way, the model assumptions are consistent with a scenario of progressive increase in atmospheric $\mathrm{CO}_{2}$.

\section{MODEL RESULTS}

The model was integrated for $30 \mathrm{yr}$ according to the length of the forcing time-series described in Section 2, both for the present-day climate (Control, 1970-1999) and future climate (Scenario, 2060-2089). The initial conditions for both runs were obtained by running the Control experiment for $5 \mathrm{yr}$ and using the model output of the last day of the integration as initial values for all the pelagic and benthic biogeochemical values. The spin-up time of 5 yr was found to be sufficient to obtain a satisfactory equilibrium between the imposed surface-forcing functions and the benthic pools.

\subsection{Analysis of the present-day ecosystem behaviour}

Before proceeding any further in the analysis of the system response to future and more uncertain conditions, it is important to make sure that the numerical model is able to reproduce the main ecosystem dynamics under the present-day conditions, for which we have field observations to compare. This is a necessary check in order to test whether the model assumption and limitations, such as the reduced number of dimensions, are appropriate for describing the system evolu- 


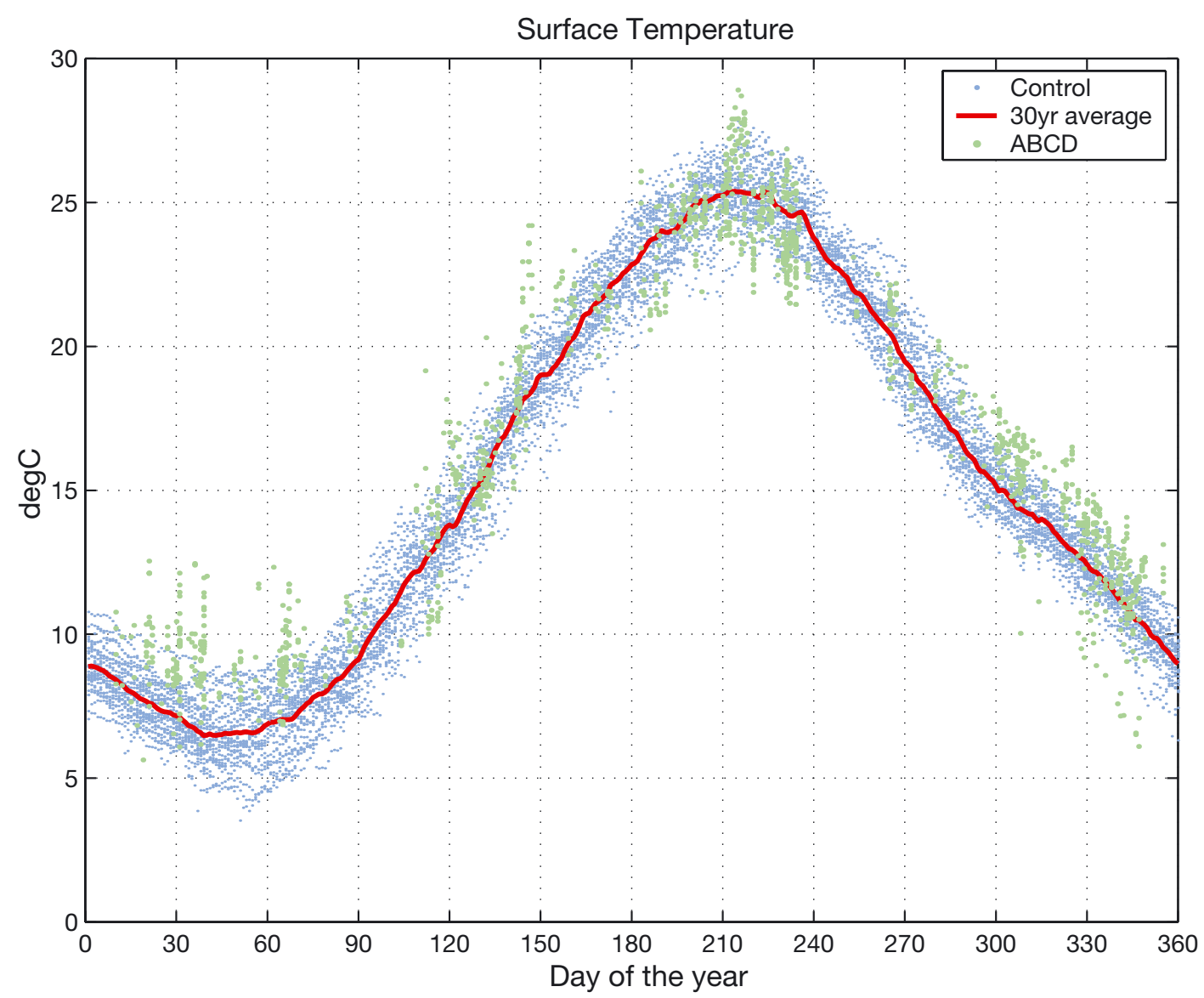

Fig. 4. Comparison of the simulated present-day (control experiment) sea-surface temperature concentration with the observed basin values from the ABCD (Adriatic BiogeoChemical Dataset). Continuous thick red line is the computed average of the $30 \mathrm{yr}$ simulation; small blue dots are the ensemble of model trajectories; and large green dots are the ABCD observations

tion. Model variables were therefore compared with the corresponding time-series of historical observations for the whole NAD derived from the ABCD (Zavatarelli et al. 1998), and the model performance was evaluated. Figs. 4 to 7 show the comparisons for SST, oxygen saturation, phosphate (surface and the bottom) and chlorophyll a (chl $a$; only surface), respectively. Model results are represented by the daily averaged value for each day of the year of every simulation year, considering a year of $360 \mathrm{~d}$ as prescribed by the original atmospheric data from the time-slice simulation. The long-term $30 \mathrm{yr}$ climatology from model results was superimposed.

The overall behaviour of the $1 \mathrm{D}-\mathrm{V}$ model is satisfactory in all the considered variables. The observed seasonal cycle of SST (Fig. 4) is well matched by the model, in the amplitude of the scattering around the mean value as well, hinting to an appropriate simulation of the surface-exchange fluxes. The model predicts SSTs of about $2^{\circ} \mathrm{C}$ less than observed during February (Days 30-60), but the overall model be- haviour is satisfactory. The positive bias of about $3^{\circ} \mathrm{C}$ with respect to the ECMWF re-analysis reported by May (2001) in the mean air temperature over Europe is apparently not hampering the simulation of the average SST in this specific implementation in the NAD.

Dissolved biogeochemical components such as oxygen (Fig. 5) or phosphate (Fig. 6) are determined by the interaction of physical transport processes and biogeochemical consumption/production terms. Thus, their correct temporal evolution indicates the skill of the coupled model in capturing the biogeochemical cycles of such elements. Both model-simulated oxygen and phosphate concentration in the Control experiment are within the range of the observed space/time variability, although the interannual variability predicted by the model is quite reduced with respect to the observations. The seasonal signal of the surface $\mathrm{O}_{2}$ concentration (Fig. 5) is clear in the observations and reasonably matched by the model. The spring increase is a consequence of the phytoplank- 
ton bloom and the average behaviour is appropriately captured. The summer oxygen consumption appears instead to be slightly underestimated, suggesting that the production phase is an overall mean feature in the basin, while the organic matter decomposition occurs either in more localized areas or as short-term events. Such spatial inhomogeneities can, however, not be captured by the 1-dimensional approach used in this study. The simulated bottom oxygen concentration (Fig. 5, bottom) is always in the upper range of the swarm of observations and does not show the extreme summer oxygen depletion found in the observations. These low values belong to the more coastal stations of the data set. It appears reasonable that the 1-dimensional approximation is better suited for the simulation of the central areas of the basin that are far from the contribution of high-frequency river inputs and other short-term coastal processes.
Thus, we cannot expect the $1 \mathrm{D}-\mathrm{V}$ model to reproduce all of the observed variability in the entire basin, but only to match the average behaviour.

Similar considerations apply to dissolved phosphate (Fig. 6), where the high natural variability found in the basin spans several orders of magnitude. Phosphate is considered to be the limiting nutrient in the Adriatic, and its spatial and temporal distribution is mainly determined by biological processes and river input (Zavatarelli et al. 1998). There is no clear seasonality in the observations, and the data could be fit at first order by a straight line. The simulated surface concentration has a weak interannual variability (except in spring) but is always within the observed range of variability, although the winter concentrations are slightly higher than the observations both at the surface and the bottom. The breaking of the stratification in autumn is indicated by the rapid increase at the surface and the depletion at the
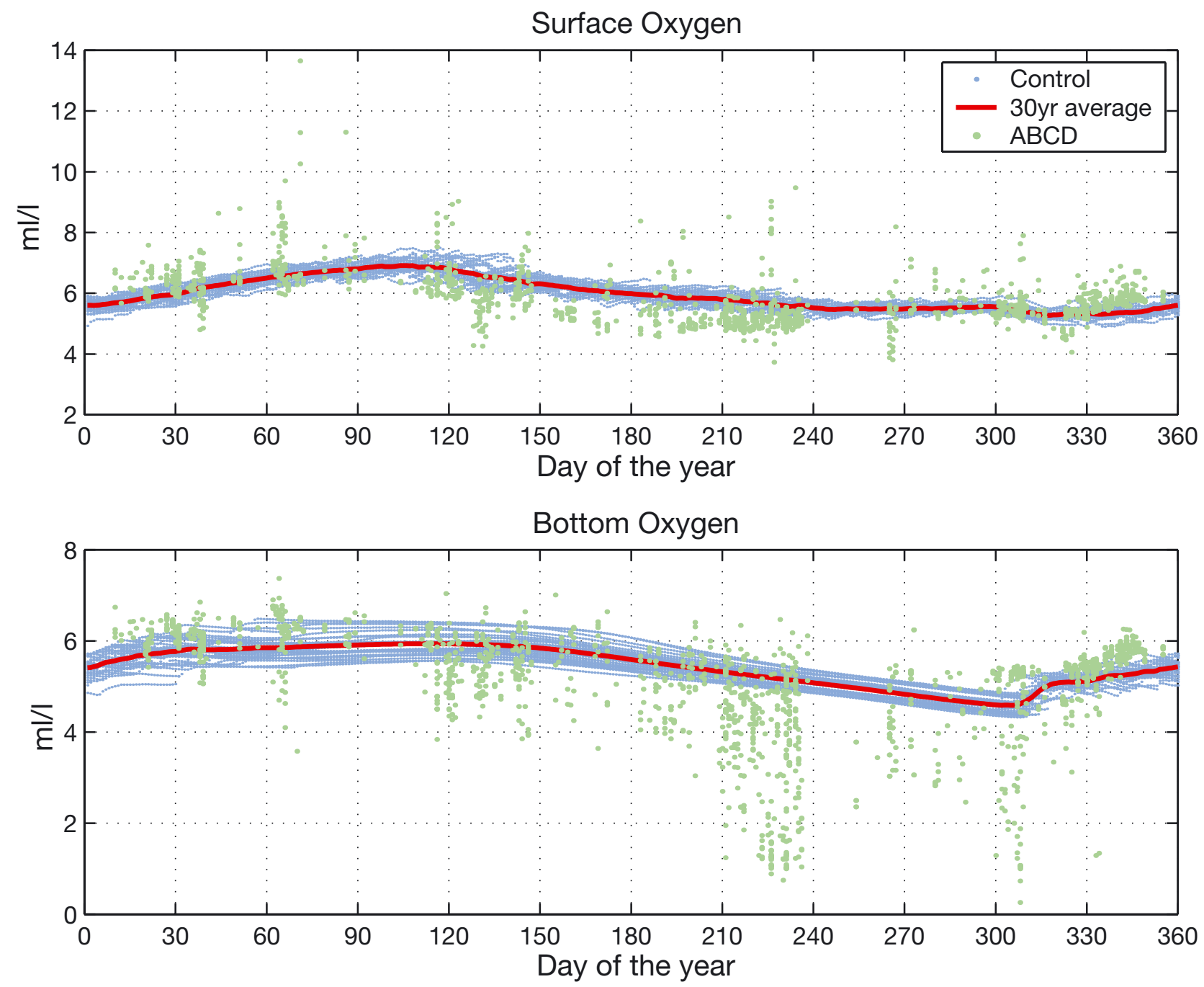

Fig. 5. As in Fig. 4, but for surface and bottom dissolved oxygen concentrations 

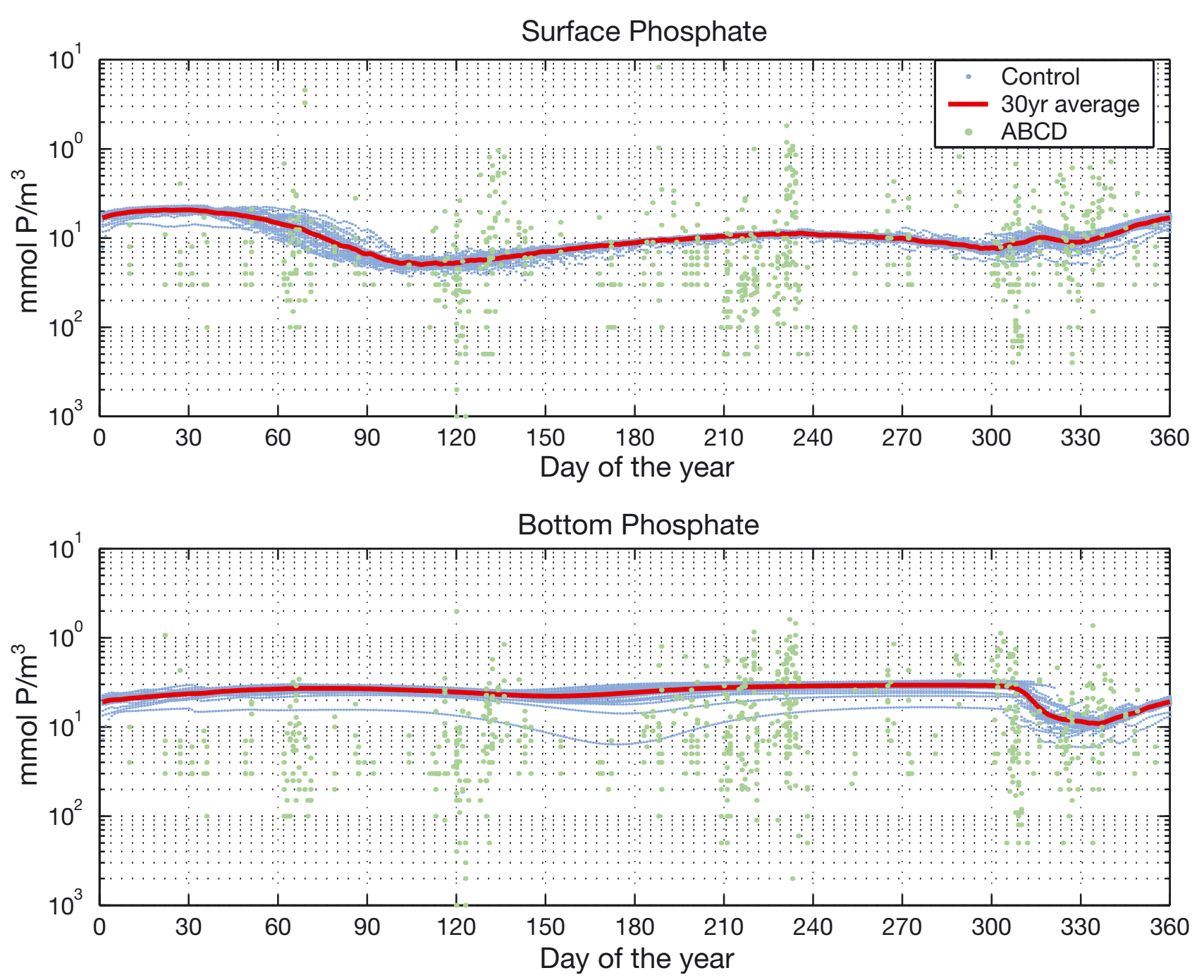

Fig. 6. As in Fig. 4, but for surface and bottom phosphate concentrations. Model results and data are compared using a semilogarithmic plot because of the observed large range of variability in the basin

bottom of the modelled phosphate concentration. This feature is also found in the observations, suggesting that the discrepancy found in winter can be due to the inappropriate representation of horizontal advection processes that remove nutrients from the area.

The variable that shows the largest interannual variability is chl $a$, whose behaviour at the surface is shown in Fig. 7. Unfortunately, the scarcity of data does not allow us to distinguish any clear seasonal variability from the available observations in the basin, while the model shows a marked development of phytoplankton blooms in spring and autumn. The main discrepancy here concerns the summer period, in which there seems to be substantial variability in the observed biomass evolution, probably due to the aggregation of data from different areas. However, the model is in overall good agreement with other long-term analysis of chl a data by Degobbis et al. (2000). Data collected on a transect from the Po delta to the Croatian coast show that the climatological mean values of phytoplankton biomass are comparable with the simulation both in the timing of the autumn/spring blooms and in the magnitude of the summer standing stocks, indicating the satisfactory behaviour of the model in simulating the main features of primary producers in the NAD.

\subsection{System response to the climate change scenario}

The analysis of the ecosystem response to the changes in the abiotic conditions as driven by the increased GHG scenario was done by focusing on 


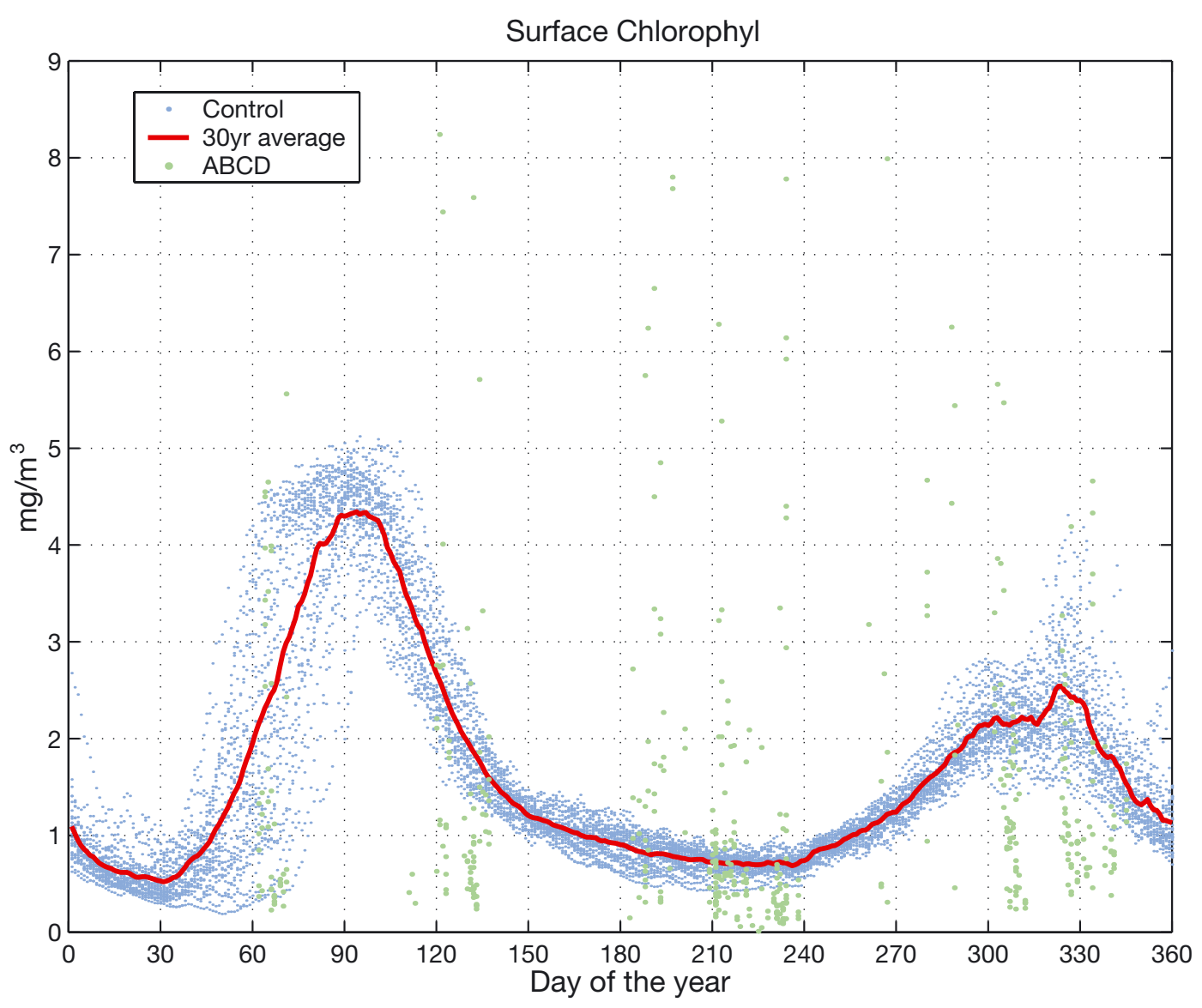

Fig. 7. As in Fig. 4, but for surface chlorophyll a

some key aspects of the ecosystem functioning. We first identified the main changes occurring in the dynamics of the water column and then the related modifications in the NAD ecosystem behaviour. Since the complex ecosystem model carries several important pelagic and benthic components of the marine ecosystem, more information on other biogeochemical processes can be extracted and analyzed from the large amount of model output. However, for the sake of simplicity, we limited the present study to the role of primary producers and the main consequences in the overall water quality of the basin, leaving extension of the investigation, especially analysis of benthic-system behaviour, to future studies.

The time-series of predicted meteorological data from the 2060-2089 time-slice simulation in the NAD show a clear increase in the $2 \mathrm{~m}$ air temperature (about $3^{\circ} \mathrm{C}$ on average), in agreement with the mean change over Europe computed by May (2001), a general reduction in mean wind speed and a small decrease in cloud cover. The application of surface boundary fluxes driven by such meteorological forcings leads to the development of the SST evolution depicted in Fig. 8. The annual SST av- erages increase in the $30 \mathrm{yr}$ Control experiment from 15 to $16^{\circ} \mathrm{C}$, with a marked interannual variability. The Scenario simulation shows a decreased variability but a steady linear increase in temperature from $18^{\circ} \mathrm{C}$ to more than $19^{\circ} \mathrm{C}$. The main difference between the 2 runs with regard to seasonal behaviour is an overall increase in the summer stratification conditions. This is mainly caused by the combined effect of increased SST and reduced wind speed during this period. The direct effect of precipitation is negligible in the present implementation.

We have quantified the increase in the stratification by calculating the density difference between the bottom and the surface layers in both experiments. Fig. 9 shows the annual average of this difference, where the increase of $0.2-0.3 \sigma_{\mathrm{t}}$ units on average is evident in 2060-2089 with respect to the Control run. There is an exception in 2076-2079 where the annual average value in the Scenario is comparable with the Control, indicating that the overall water-column temperature in the Scenario is indeed higher than in the Control but the stratification condition (i.e. the density gradient) is similar. The average difference between present and future conditions is significant in terms of the range of densities found in the 


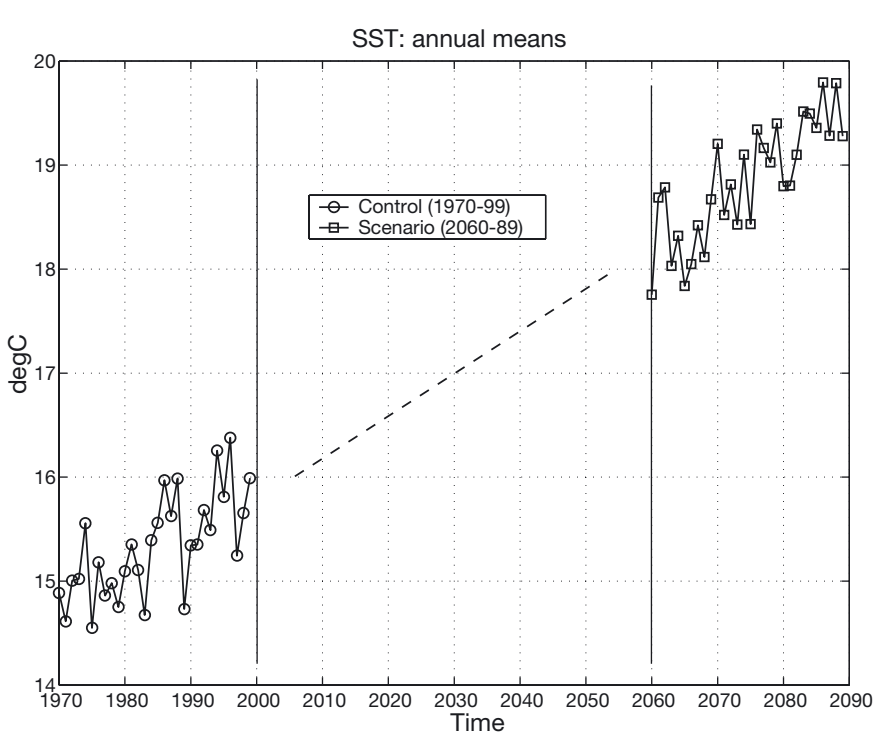

Fig. 8. Annual means of sea-surface temperature (SST) simulated by the $1 \mathrm{D}-\mathrm{V}$ model in the 2 time-slice experiments

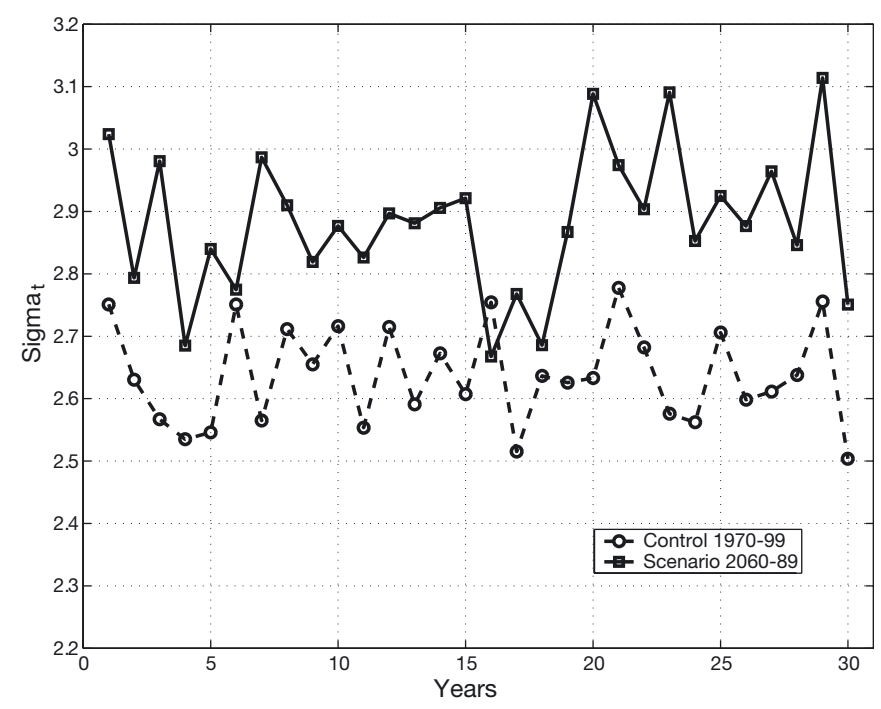

Fig. 9. Simulated density difference between bottom and top layers in the Control and Scenario experiments. Annual means over the 2 considered time-slice simulations

basin (Artegiani et al. 1997), and the 1-dimensional approximation is sufficient to get a general overview of the expected modifications in the system. In general, the occurrence of more stable stratified conditions has consequences for both the diapycnal diffusion of dissolved constituents between surface and bottom waters and the confinement of phytoplankton in the euphotic layer, the latter enhancing the primary production. The effect of the stronger stratification on the dissolved oxygen behaviour is depicted in Fig. 10, where the oxygen saturation at the bottom of the water column is shown. Notwithstanding the small difference in the average

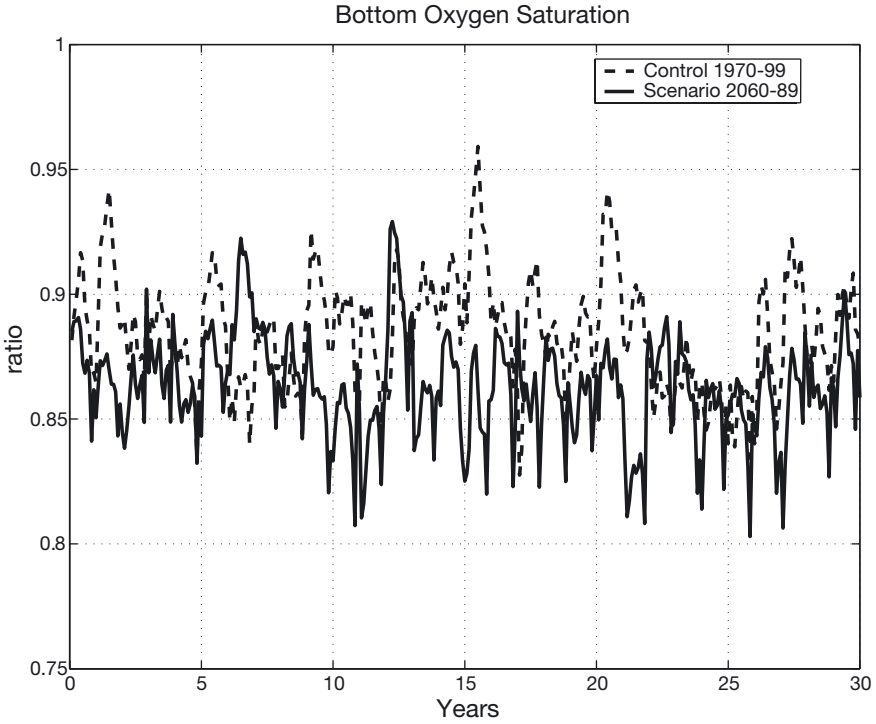

Fig. 10. Monthly mean values of the oxygen saturation at the bottom in the Control and Scenario experiments

concentration in the 2 time-series, which indicates sufficient oxygenation of the bottom layer, the values predicted by the model in the future-climate Scenario show an overall decrease in oxygen saturation. Especially the summer values are, as expected, lower in the Scenario, and the autumn/winter recovery due to the breaking of the stratification is not present in all the years, in contrast to the Control time-series. As it will be shown in the next section, the annual average biomass of the phytoplankton standing stock is not significantly different in the 2 runs, and this is also the case for the export flux of organic particles from the euphotic zone. Therefore, the decrease in the oxygen bottom saturation is mainly due to a direct effect of the increased stratification rather than a consumption process induced by the degradation of larger amount of organic matter reaching the bottom layers. This implies that oxygen dynamics alone cannot be used as an indicator of eutrophication in the NAD; instead, it has to be used in conjunction with an estimation of the physical conditions, as already pointed out in Degobbis et al. (2000).

\subsection{Primary producers behaviour and trophic structure}

In this section we compare the behaviour of the primary-producer component in the future climate with the simulated present-day behaviour. Long-term climatological annual means of primary producers in the NAD over the period 1966-1986 have been analyzed by Smodlaka (1986). The average value for the basin of the phytoplankton biomass expressed as chl a concentration is $1.67 \mathrm{mg} \mathrm{m}^{-3}$, with a mean of $2.87 \mathrm{mg} \mathrm{m}^{-3}$ in the more 

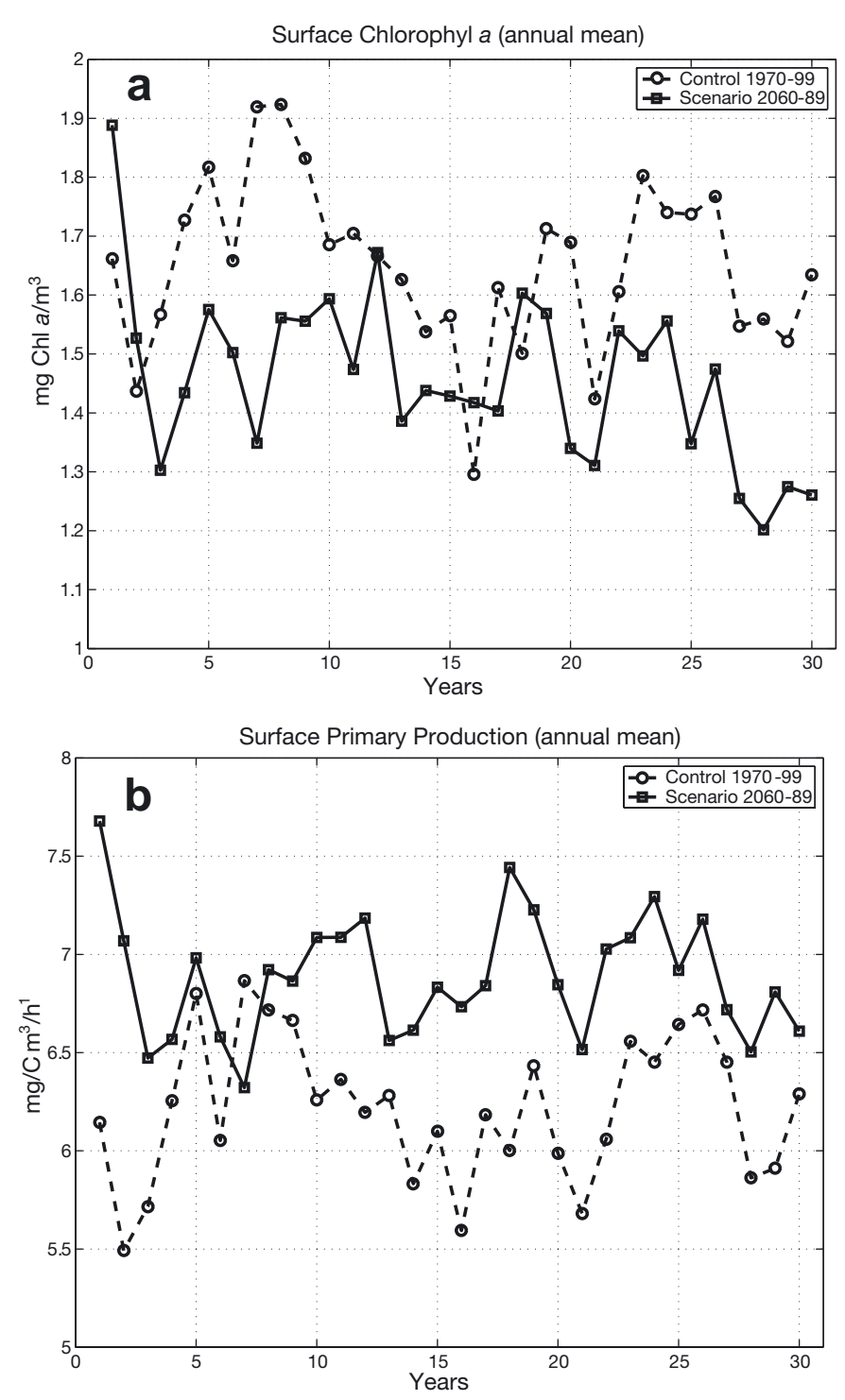

Fig. 11. Comparison between the present (Control) and future (Scenario) climate simulations. (a) Annual means of surface chl $a$ in the $30 \mathrm{yr}$ period 1970-1999 and in the period 2060-2089. (b) Annual means of surface primary production in 1970-1999 and 2060-2089

eutrophic western basin and $0.87 \mathrm{mg} \mathrm{m}^{-3}$ in the eastern one. The observed mean annual primary production in the entire northern basin is $6.6 \mathrm{mg} \mathrm{C} \mathrm{m}^{-3} \mathrm{~h}^{-1}$, ranging from $2.8 \mathrm{mg} \mathrm{C} \mathrm{m}^{-3} \mathrm{~h}^{-1}$ in the eastern part to $11.8 \mathrm{mg} \mathrm{C}$ $\mathrm{m}^{-3} \mathrm{~h}^{-1}$ in the west. The values predicted by the model in both experiments are in very good agreement with the available observations (Fig. 11). The comparison between the phytoplankton biomass expressed as chl a (Fig. 11a) shows an overall slight decrease in surface annual mean values in the Scenario. The relative range of variability in the annual mean time-series is comparable in both experiments. Chl a shows a small negative trend

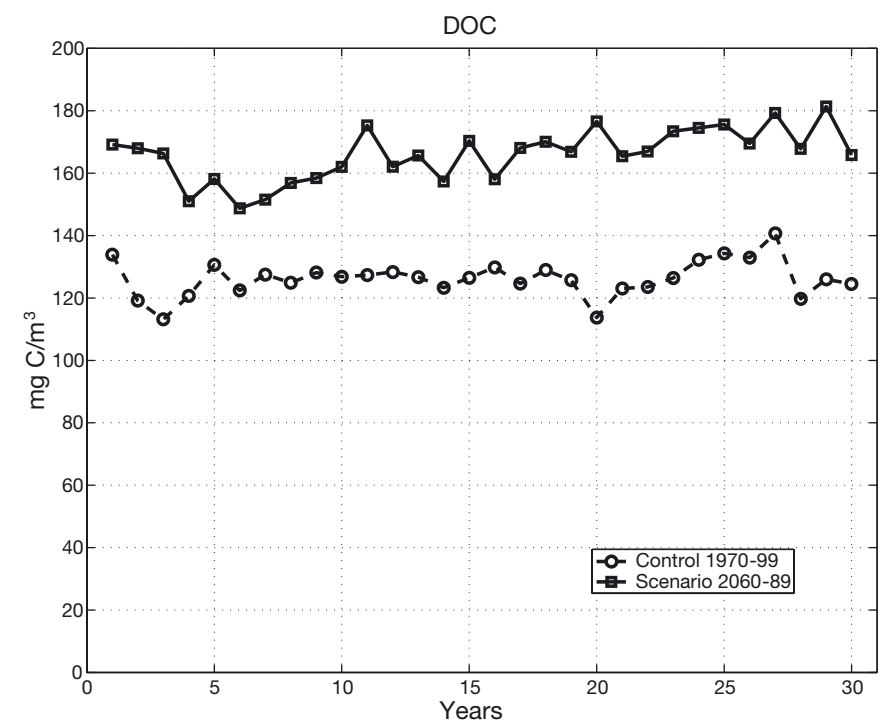

Fig. 12. Dissolved organic carbon (DOC) in the Control and Scenario experiments. Depth-averaged annual means over the 2 considered time-slice periods

in the last $10 \mathrm{yr}$ of the Scenario, although the interannual variability is still evident. On the contrary, the simulated surface annual mean primary production rates show an increase in the Scenario with respect to the Control experiment. The model gives higher specific production rates under future climate conditions, indicating increased inorganic carbon uptake by the primary producers. However, the phytoplankton standing stock has not increased accordingly. The overall stronger stratification enhances the carbon fixation because the mixed layer is within the euphotic zone for longer periods, but at same time it reduces the nutrient availability from the bottom layers. This mechanism induces the modelled phytoplankton to excrete a large part of the photosynthesized carbon because there are not enough nutrients to carry on the transformation into structural cellular proteins. It is important to note that such a feature of the carbon cycling can be described by the model because of the realistic parametrization of the decoupled uptake dynamics of nutrients and carbon (Baretta-Bekker et al. 1997). In the case of nutrient imbalance, carbon is released by phytoplankton in the form of dissolved organic carbon (DOC), and we see that the Scenario experiment shows a marked increase in the water-column average of DOC content with respect to the Control (Fig. 12). The Scenario annual mean increases by $30 \%$ on average with respect to the Control and shows a slight linear positive trend.

Generally, an increased availability of DOC may indicate an overall shift of the food-web structure towards microbial processes (Puddu et al. 2000). Indeed, the model gives some indications of possible changes in the biomass distribution of the phytoplank- 
ton classes. Fig. 13 shows the annual means of the average water-column concentrations of phytoplankton carbon biomasses divided into the main functional groups carried by the model, namely microphytoplankton (i.e. diatoms), nanophytoplankton (i.e. autotrophic nanoflagellates) and picophytoplankton. The main differences between the Control and Scenario experiments concern the interannual variability and the abundance of the picophytoplankton size class. The model predicts a flattening of the interannual variability in the Scenario together with an overall reduction of total biomass, as already pointed out in the chl a evolution of Fig. 11a. There is also a small increase in the nanoplankton fraction with respect to diatoms, which is not clearly visible in the histogram representation but can be seen by analyzing the relative percentages. Thus, the instauration of more stable stratification conditions throughout the year appears to inhibit the interannual changes in the distribution of phytoplanktonic groups and to favour those phytoplankton classes that are typical of summer conditions such as nanoflagellates. The model also predicts a marked reduction of the picophytoplankton abundance under the future climate conditions (Fig. 13). The picophytoplankton group has only recently been identified and classified during phytoplankton counts, and its climatological variability in the NAD is mostly unknown. In northern seas such as the North Sea and the Baltic, this fraction is associated with a well-mixed
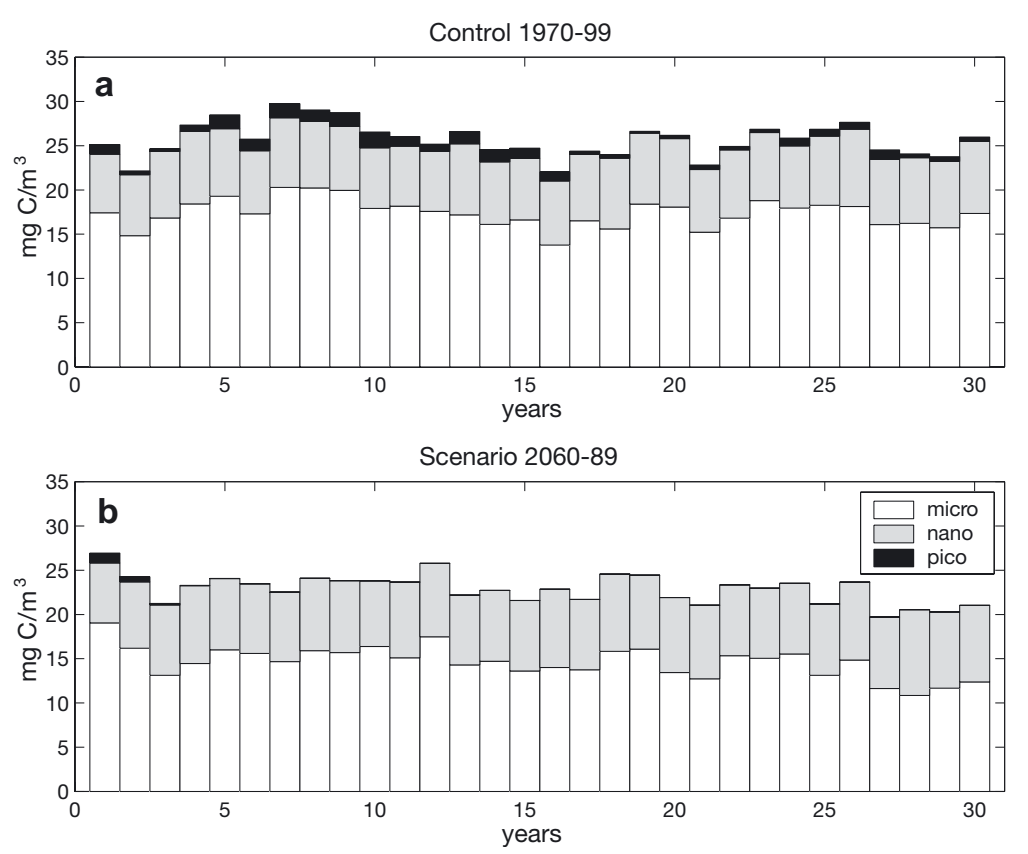

Fig. 13. Annual means of phytoplankton size-class distributions expressed as water-column averages of biomasses (a) Control and (b) Scenario water column, and a bloom of picophytoplankton usually precedes the development of the spring diatom bloom. Its disappearance in the Scenario can again be related to the presence of a more stratified water column that partially persists throughout the winter period. However, the importance of this size fraction in the NAD dynamics needs to be clarified by further experimental studies, and the present results have to be considered as exploratory with regard to the possible changes in the size structure of the autotrophic system.

\subsection{Sensitivity experiments on the BFM formulation}

The uncertainties related to the choice of the model formulation need to be discussed more extensively. Interactions among communities and species may modify the response to the warming signal, and we do not know how marine ecosystems of different complexity will react to the anticipated climate conditions (Petchey et al. 1999). We are also interested in analyzing the capabilities of this complex BFM to elicit the behaviour observed in natural marine ecosystems. In this section we show results of a set of sensitivity experiments on the model formulation meant to analyze (1) whether the primary producers response is directly linked to the increase in SST (by a direct increase in physiological production rates, for instance, or by the heat-induced more favourable stratification conditions), and (2) whether the structure of the food web could alter this response, leading to the less predictable behaviour typical of natural systems (Solé et al. 1999).

Several combinations of model components were tested and forced with the same meteorological and nutrient forcing functions used in the Control and Scenario standard experiments. Table 1 presents a selected set of the sensitivity experiments performed. The numerical experiments simulate the behaviour of food webs of increasing complexity, intended as number of trophic level interactions, in 0-dimensional and 1-dimensional abiotic environments. We will not discuss here the simulations with homogeneous physics (0-dimensional), whose main results can also be obtained with the 1-dimensional simulations. The main differences in this case lie in the absolute values of model variables that are much higher for the 0-dimensional simulations. This result would lead us to the preliminary conclusion that the indirect effects of the warming signal (enhancement 
Table 1. Sensitivity experiments on the choice of the BFM formulation. Model state variable symbols are given in Fig. 3 and were grouped as follows: $\mathrm{P}=\mathrm{P} 1, \mathrm{P} 2, \mathrm{P} 3 ; \mathrm{N}=\mathrm{N} 1, \mathrm{~N} 3, \mathrm{~N} 4, \mathrm{~N} 5$; $\mathrm{Z}=\mathrm{Z3}, \mathrm{Z4}, \mathrm{Z} 5, \mathrm{Z6}$; D = R1，R6. 0D: a 0-dimensional set-up simulating a fully mixed box model forced with the Control and Scenario SST and nutrient boundary conditions. 1D: the

1-dimensional set-up used in the standard simulations

\begin{tabular}{|c|c|c|}
\hline Name & Components & Physics \\
\hline Standard & $\mathrm{P}, \mathrm{Z}, \mathrm{N}, \mathrm{B}, \mathrm{D}$, benthic model & $1 \mathrm{D}$ \\
\hline E1 & $P, N$ & OD \\
\hline E3 & $\mathrm{P}, \mathrm{Z}, \mathrm{N}, \mathrm{B}, \mathrm{D}$ & OD \\
\hline E4 & $\mathrm{P}, \mathrm{N}$ & $1 \mathrm{D}$ \\
\hline E5 & $\mathrm{P}, \mathrm{Z}, \mathrm{N}$ & $1 \mathrm{D}$ \\
\hline E6 & $\mathrm{P}, \mathrm{Z}, \mathrm{N}, \mathrm{B}, \mathrm{D}$ & $1 \mathrm{D}$ \\
\hline E7 & $\mathrm{P} 1, \mathrm{Z}, \mathrm{N}, \mathrm{B}, \mathrm{D}$, benthic model & $1 \mathrm{D}$ \\
\hline
\end{tabular}

of stratification, etc.) are mainly reflected in the absolute values of phytoplankton growth, and this fact does not substantially modify the physiological response of the phytoplankton.

The combinations of state variables go from a simple model of 3 phytoplankton functional groups plus nutrients (E4) to a progressive addition of functional groups as in E5 (zooplankton plus 0-order nutrient remineralization) and E6 (similar to the standard runs but without benthic dynamics). We also discuss an experiment (E7) which is identical to the standard runs, except that we reduced the intra-functional diversity, using only 1 phytoplankton group (diatoms: P1) instead of 3.
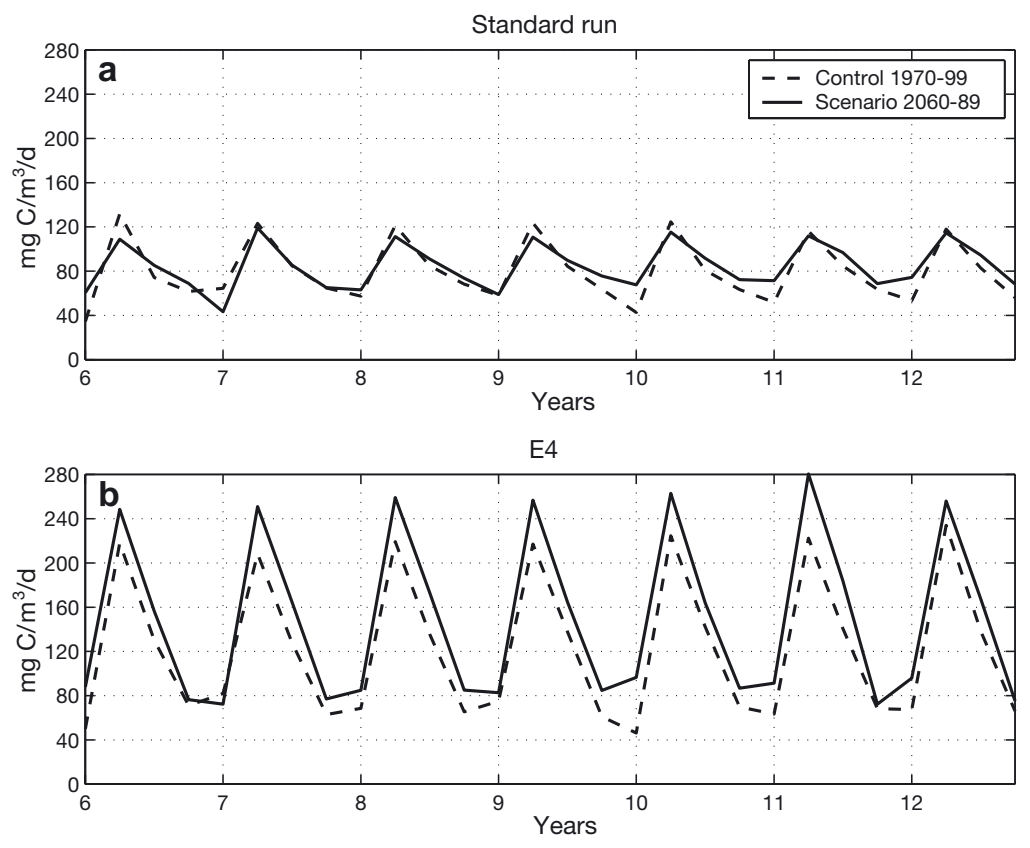

Fig. 14. Sensitivity experiments on the ecosystem-model structure formulation (see Table 1). Seasonal means of surface gross primary production (GPP) for (a) the standard runs and (b) E4
All the experiments were run for $12 \mathrm{yr}$ for both the Control and the Scenario forcing functions, and we analyzed the results from Years 6 to 12, corresponding to the interval 1976-1982 in the Control and the interval 2066-2072 in the Scenario. The key variable that was chosen to investigate the response of phytoplankton is the gross primary production (GPP), which determines the inflow of inorganic carbon into the ecosystem and its potential transformation into organic particles. The parametrized form of this model diagnostic is (Vichi 2002):

$$
\mathrm{GPP}=r_{0}\left(f_{\mathrm{s}}\right) f_{\mathrm{I}} Q_{10}^{\frac{T-T_{0}}{T_{0}}} P
$$

where $P$ is phytoplankton concentration (in $\mathrm{mg} \mathrm{C} \mathrm{m}^{-3}$ ), $r_{0}$ is the potential specific growth rate $\left(\mathrm{in}^{-1}\right)$ at $T_{0}=$ $10^{\circ} \mathrm{C}$ under optimal light conditions, $f_{\mathrm{I}}$ is a regulating factor for light ranging from 0 to 1 and computed according to Ebenhöh et al. (1997), $Q_{10}$ is the characteristic temperature coefficient set to 2 and $f_{\mathrm{s}}$ is a regulating factor for silicate availability, written in a Michaelis-Menten form and only valid for diatoms. As described above, the dynamics of carbon uptake are decoupled from nutrients. Thus, there is no direct dependency of the phytoplankton state variables on the external nutrient concentrations, apart for structural silica in the case of diatoms. Nutrient availability, both intracellular and external, regulates the assimilation of carbon and therefore is included in the calculation of the loss terms and in the final value of biomass (see also Baretta-Bekker et al. 1997, Vichi 2002). The potential growth rates are different for the 3 modelled phytoplankton groups, being 2.5, 2.7 and 4.0 $\mathrm{d}^{-1}$ for diatoms, flagellates and picophytoplankton, respectively. We have considered the total GPP as the sum over all the functional groups of the GPP variable in Eq. (1).

Fig. 14 shows the time evolution of the seasonally averaged GPP for the standard run compared with E4. The response of a phytoplankton-only community (Fig. 14b) shows a more steady enhancement of production rates (about $25 \%$ more on average) induced by the higher SST values, with a reduced seasonal and interannual variability. The higher spring peaks are the consequence of the absence of herbivores, leading to higher phytoplankton biomasses. On the contrary, in the standard run the increase in GPP is mainly found during summer, reducing the mean difference between Control and Scenario to $10 \%$ over the 
E7

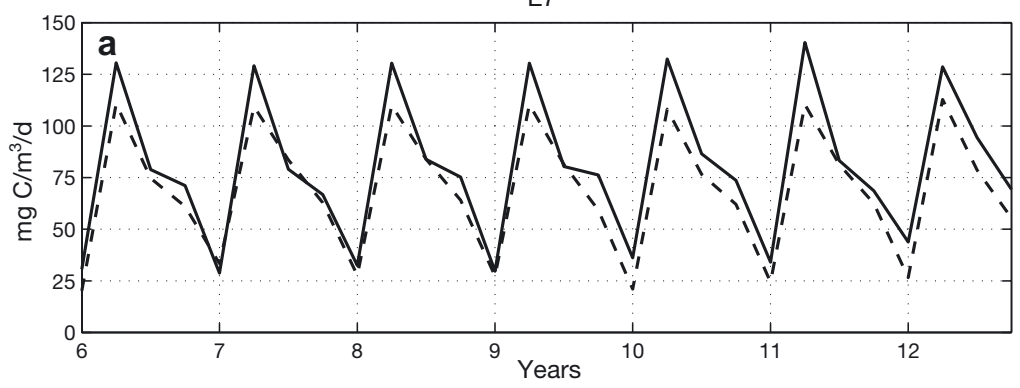

E5

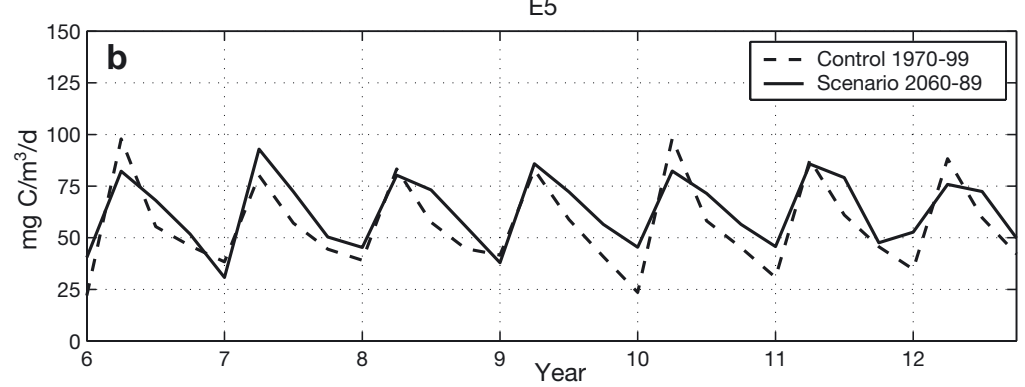

Fig. 15. Sensitivity experiments on the ecosystem-model structure formulation (see Table 1). Seasonal means of surface GPP for (a) E7 and (b) E5

assessment of the impact of future climate conditions has to be done under consideration of ensembles of simulations with different compositions of the relevant system variables. An oversimplification of the biogeochemical processes could, in fact, result in incorrect estimations of major carbon fluxes through the food web.

\section{DISCUSSION}

In this exploratory work we have analyzed the response of a complex ecosystem model of the northern Adriatic Sea to a climate change scenario. The presentday and the scenario forcing functions have been taken from greenhouse gas simulations with a high-resolution global AGCM and used to force a 1D-V physical model of the northern Adriatic Sea. The novelty of this work is the downscaling of large-scale climate simulations to the regional scale and the coupling with a comprehensive biogeochemical model.

simulated period. An intermediate behaviour is observed in E7 (Fig. 15a). The use of a single phytoplankton functional group leads to an enhancement of the spring production under the Scenario conditions as seen in E4 (Fig. 14b). Thus, a cross-comparison with the standard run results suggests that the intra-group competition among primary producers has a buffering effect on the phytoplankton response under the Scenario conditions. The introduction of an explicit remineralization operated by a bacteria functional group also has an impact on the phytoplankton carbon uptake. The absence of a full microbial loop, as simulated in E5 (Fig. 15b), reduces the average GPP by about $30 \%$, although the differential response to the warming signal is not altered with respect to the standard simulation.

We can partly generalize the above results by saying that the non-linear interactions among the system components in the food web affect the response of primary producers to the temperature increase in the Scenario. Both the presence of more functional groups at the same trophic level and different structural organization (complexity) of the food web have an impact on phytoplankton carbon uptake under the Scenario conditions. These findings are partially in accordance with the microcosm laboratory experiments performed by Petchey et al. (1999) with a combination of different marine microbial communities. The sensitivity of the model to the different formulations of the ecosystem structure is high, implying that the model-based
This allows us to investigate the possible impact of global warming on the modelled ecosystem dynamics and carbon flows. Clearly, the results have to be critically discussed in view of the assumptions and simplifications of the model itself. Only a portion of the variability of the coupled physical/biogeochemical processes occurring in the system can be captured with a 1-dimensional approach. For instance, the 1-dimensional model can hardly account for the large source of variance induced by boundary conditions such as interannual differences in riverine inputs, changes in general circulation patterns or increased atmospheric deposition of micro- and macronutrients.

Nevertheless, the simulation of the hydrodynamical and biogeochemical system behaviour as driven by the present-day surface forcing functions (Control, 1970-1999) is in satisfactory agreement with the available time-series of observations for the main NAD system components. This implies that, in spite of the simple $1 \mathrm{D}-\mathrm{V}$ approach, the transfer of regional information from the high-resolution AGCM is sufficient to provide the observed physical variability and to capture the main biogeochemical features of the basin. The simulation of present-day dynamics is a necessary condition for the assessment of model skill in predicting the system behaviour under the global warming scenario.

Since the model only includes some aspects of the future climate scenarios, we think that the changes shown in the previous sections are a lower limit of the 
possible range of climatic changes. Some uncertainties in this study derive from the absence of an appropriate estimation of the future changes in the river runoffs and the related organic/inorganic loads. Unfortunately, there are no existing reliable estimates of these forcing functions. In the Scenario, the model predicts an overall enhancement of the water-column stratification conditions on an annual basis, with stronger intensification during the summer periods. This has consequences for the diffusion of oxygen and nutrients between surface and bottom layers. Changes in the river runoff can affect the vertical structure of the water column, and hence the turbulent diffusive transport. However, the anticipated changes are not particularly well known at present. An increase in the freshwater runoff, due for instance to an increase in snow melting in the Alps (Gregory \& Oerlemans 1998), should lead to a further strengthening of the stratification, favouring the utilization of light by phytoplankton and further dampening the diffusion of nutrients from bottom layers. However, the increase in river runoff could also lead to an increase in the input of inorganic suspended sediments and inorganic/organic nutrients. Since coastal ecosystems are generally light-limited (Legendre \& Rassoulzadegan 1995), it is possible that the turbidity of waters has more impact on phytoplankton net growth rates than nutrient availability. Nevertheless, a sensitivity analysis on the Scenario simulation indicates that, if the surface nutrient boundary conditions for all nutrients are increased by $20 \%$ without changing the suspended sediment input, the oxygen saturation values are further reduced due to the increase in spring primary production. Unfortunately, the current estimations of the future nutrient load changes are still based on simple linear extrapolation (de Wit \& Bendoricchio 2001); therefore the reliability of this scenario is difficult to assess.

On the other hand, recent hydrological model simulations give a possible decrease in the runoff of the southern European rivers for the future climate, consistent with a general decrease in precipitation in these regions over all the seasons but winter (May et al. 2002). In particular, the reduction of discharge is evident in March to June (about $30 \%$ ), reducing the seasonal variability of the freshwater signal and presumably making the basin more open-sea like. We have preliminarily tested this scenario in the model by relaxing it to a constant surface salinity value (the long-term climatological mean of the basin), thus mimicking the decreased influence of lowsalinity waters. The resulting oxygen concentration (not shown) at the bottom is as low as in the experiment with the increased nutrient load, but in this case it is the summer production that increases the biochemical oxygen demand. Because of the lower freshwater input, the stratification is fairly low during summer and the diffu- sion of oxygen to the depleted lower layers is enhanced. However, at the same time the intensified turbulent diffusive transport increases the availability of nutrients in the surface euphotic layers. Hence we have an increase in the summer phytoplankton biomass and an intensification of the export of organic particles to the bottom layers, both leading to a higher biological oxygen demand that exceeds the oxygen diffusion.

Thus, the model is suggesting that 2 opposite trends in the forcing functions would have the same effect on the ecosystem dynamics. All these speculations on the possible influences indicate that the unknown factors are manifold, and therefore a comprehensive model is strongly needed for assessing the contribution of each one of them. The present experiment considers only the impact of increased stratification due to the regional effect of a global-warming scenario. Nevertheless, it shows some interesting results that cannot be investigated by using a simple NPZD (nutrient, phytoplankton, zooplankton and detritus) model. The parametrization of detailed physiological processes of algae and the closure of the microbial loop dynamics can give some indications for the possible indirect effects on the biogeochemical cycles. The annual mean behaviour of modelled phytoplankton groups under the Scenario conditions shows an increase in GPP rates and a small decrease in the standing-stock biomasses. The specific phytoplankton uptake of inorganic carbon is thus increased, but this organic carbon is transferred to the food web in the form of DOC because of the reduced supply of nutrients due to the more stratified conditions. The mean annual concentration of DOC is considerably higher in the Scenario, and an increase in the DOC concentration could lead to changes in the water quality. In fact, an accumulation of DOC is thought to be a necessary pre-condition for mucilage formation in the Adriatic (Azam et al. 1999, Degobbis et al. 1999). The model also responds by shifting the trophic structure towards heterotrophic microbial loop processes, which are typical of more stratified systems (Legendre \& Rassoulzadegan 1995).

The sensitivity experiments described in Section 5.4 show that the simulated primary producers' response to different climate conditions depends on the formulation of the ecosystem structure implemented in the model. The response of phytoplankton to an increase in the environmental temperature is modulated by the non-linear biogeochemical interactions among system components, and thus it is difficult to obtain unique scientific answers regarding the system behaviour. The use of comprehensive marine ecosystem models carrying several state variables is therefore recommended, as such systems can develop different patterns of the matter fluxes and allow different structures of the marine ecosystem to be set up, which can be used to derive an ensemble of simulations. 


\section{FINAL REMARKS}

The present model is a first step towards the understanding of complex interactions in coastal ecosystems affected by a global warming scenario, and it can be of help in addressing some preliminary hypotheses and deciding the future lines of research. These findings, valid for this specific model study applied to the northern Adriatic Sea, can be partially extended to other semi-enclosed or enclosed shelf basins. The use of a generic ecosystem model structure, such as the one in ERSEM, gives some indications of a possible shift in the organicmatter cycling in this coastal ecosystem in a scenario of increased thermal stratification. These model results are in accordance with recent findings from a microcosm laboratory experiment that analyzed the alteration of food-web structures due to environmental warming conditions. Petchey et al. (1999) report that changes in the relative distribution of organisms among functional groups lead to differences in ecosystem function beyond those expected from temperature-dependent physiological rates. Complex system responses generated in real ecosystems complicate inferences based on single functional groups, and we cannot expect that the structure of coastal ecosystems will remain unchanged while going through modifications in the abiotic environmental conditions. Even if in the future we were able to define a highly refined set of climate change scenarios with a proper spatial and temporal resolution, we would always have to face the problem of dealing with the functional adaptations of the biological components of coastal ecosystems by using a deterministic approach. However, results of this present study have shown that it is feasible to capture some of such complex interactions, increasing the degree of confidence with regard to the capabilities of comprehensive coupled ecosystem models in the analysis of the marine environment behaviour under future climatic changes.

Acknowledgements. This work has been financed by the Italian Ministry for the Environment and Territory in the framework of the project CAIEDAS (Climatic and Anthropogenic Impacts on the Environmental Dynamics of the Adriatic Sea) coordinated by the National Institute for Geophysics and Volcanology (INGV).

\section{LITERATURE CITED}

Allen JI, Blackford JC, Radford PJ (1998) A 1-D vertically resolved modelling study of the ecosystem dynamics of the middle and southern Adriatic Sea. J Mar Syst 18: 265-286

Allen JI, Howland RHM, Bloomer N, Uncles RJ (1999) Simulating the spring phytoplankton bloom in the Humber Plume (UK). Mar Pollut Bull 37:295-305

Artegiani A, Bregant D, Paschini E, Pinardi N, Raicich F, Russo A (1997) The Adriatic Sea general circulation. Part II: baroclinic circulation structure. J Phys Oceanogr 27: $97-114$
Azam F, Fonda Umani S, Funari E (1999) Significance of bacteria in the mucilage phenomenon in the northern Adriatic Sea. Ann Ist Super Sanità 35:411-419

Baretta JW, Ebenhöh W, Ruardij P (1995) The European Regional Seas Ecosystem Model, a complex marine ecosystem model. Neth J Sea Res 33(3/4):233-246

Baretta-Bekker JG (ed) (1995) European Regional Seas Ecosystem Model I (1990-1993). Neth J Sea Res 33(3/4):229-483

Baretta-Bekker JG, Baretta JW (eds) (1997) European Regional Seas Ecosystem Model II (1993-1996). J Sea Res 38(3/4):169-436

Baretta-Bekker JG, Baretta JW, Ebenhöh W (1997) Microbial dynamics in the marine ecosystem model ERSEM II with decoupled carbon assimilation and nutrient uptake. J Sea Res 38(3/4):195-212

Bhaud M, Cha JH, Duchene JC, Nozais C (1995) Influence of temperature on the marine fauna: what can be expected from a climatic change? J Therm Biol 20(1-2):91-104

Blumberg AF, Mellor GL (1987) A description of a threedimensional coastal ocean circulation model. In Heaps NS (ed) Three-dimensional coastal ocean model. American Geophysical Union, Washington, DC, p 1-16

Castellari S, Pinardi N, Leaman K (1998) A model study of air-sea interactions in the Mediterranean Sea. J Mar Syst 18:89-114

de Wit M, Bendoricchio G (2001) Nutrient fluxes in the Po basin. Sci Total Environ 273:147-161

Degobbis D, Malej A, Fonda Umani S (1999) The mucilage phenomenon in the northern Adriatic Sea: a critical review of the present scientific hypotheses. Ann Ist Super Sanità 35:373-381

Degobbis D, Precali R, Ivancic I, Smodlaka N, Fuks D, Kveder S (2000) Long-term changes in the northern Adriatic ecosystem related to anthropogenic eutrophication. Int J Environ Pollut 13:495-533

Dobson FW, Smith SP (1988) Bulk model of solar radiation at the sea. Q J R Meteorol Soc 114:165-182

Droop MR (1973) Some thoughts on nutrient limitation in algae. J Phycol 9:264-272

Ebenhöh W, Baretta JG, Baretta JW (1997) The primary production module in the marine ecosystem model ERSEM II with emphasis on the light forcing. J Sea Res 38:173-193

Falkowski P, Scholes RJ, Boyle E, Canadell J, and 13 others (2000) The global carbon cycle: a test of our knowledge of Earth as a system. Science 290:291-296

Fonda Umani S (1996) Pelagic production and biomass in the Adriatic Sea. Sci Mar 60:65-77

Galperin B, Kanta LH, Hassid S, Rosati A (1988) A quasi-equilibrium turbulent energy model for geophysical flows. J Atmos Sci 45:55-62

Gregory JM, Oerlemans J (1998) Simulated future sea-level rise due to glacier melt based on regionally and seasonally resolved temperature changes Nature 391:474-476

HELCOM (1990) Second periodic assessment of the state of the marine environment of the Baltic Sea, 1984-1988; background document. Baltic Sea Environ Proc No. 35 B, HELCOM, Helsinki

HELCOM (1996) Third periodic assessment of the state of the marine environment of the Baltic Sea, 1989-1993; background document. Baltic Sea Environ Proc No. 64 B, HELCOM, Helsinki

Houghton JT, Callandar BA, Varney SK (eds) (1992) Climate change 1992. The supplementary report to the IPCC scientific assessment. Cambridge University Press, Cambridge

Hughes L (2000) Biological consequences of global warming: 
is the signal already apparent? Trends Ecol Evol 15:56-61 Ingram RG, Wang J, Lin C, Legendre L, Fortier L (1996) Impact of freshwater on a subarctic coastal ecosystem under seasonal sea ice (southeastern Hudson Bay, Canada). I. Interannual variability and predicted global warming influence on river plume dynamics and sea ice. J Mar Syst 7:221-231

Justic D, Legovic T, Rottini-Sandrini L (1987) Trends in oxygen content and occurrence of benthic mortality in the northern Adriatic Sea. Estuar Coast Shelf Sci 25:435-445

Legendre L, Rassoulzadegan F (1995) Plankton and nutrient dynamics in marine waters. Ophelia 41:153-172

Maggiore A, Zavatarelli M, Angelucci MG, Pinardi N (1998) Surface heat and water fluxes in the Adriatic Sea: seasonal and interannual variability. Phys Chem Earth 23:561-567

Mann KH (1988) Towards predictive models for coastal marine ecosystems. In: Pomeroy LR, Alberts JJ (eds) Concepts of ecosystem ecology. Springer-Verlag, Berlin, p 291-316

May W (2001) Impact of horizontal resolution on the simulation of seasonal climate in the Atlantic/European area for present and future times. Clim Res 16:203-223

May W, Roeckner E (2001) A time-slice experiment with the ECHAM4 AGCM at high resolution: impact of horizontal resolution on annual mean climate change. Clim Dyn 17: $407-420$

May W, Voss R, Roeckner E (2002) Changes in the mean and extremes of the hydrological cycle in Europe under enhanced greenhouse gas conditions in a global time-slice experiment. In: Beniston M (ed) Climatic change: implications for the hydrological cycle and for water management. Advances in Global Change Research, Vol 10. Kluwer Academic Publishers, Dordrecht, p 1-29

Mellor GL, Yamada T (1982) Development of a turbulence closure model for geophysical fluid problems. Rev Geophys Space Phys 20:851-875

Melvasalo T (2000) Regional marine environmental management and the GPA-LBA: perspectives and the need for scientific support. Ocean Coast Manage 43:713-724

Nicholls RJ, Hoozemans FMJ (1996) The Mediterranean: vulnerability to coastal implications of climate change. Ocean Coast Manage 31:105-132

Nicholls RJ, Hoozemans FMJ, Marchand M (1999) Increasing flood risk and wetland losses due to global sea-level rise: regional and global analyses. Global Environ Change 9:S69-S87

Nike Bianchi C, Morri C (2000) Marine biodiversity of the Mediterranean Sea: situation, problems and prospects for future research Mar Pollut Bull 40:367-376

Obernosterer I, Ruardij P, Herndl GJ (2001) Spatial and diurnal dynamics of dissolved organic matter (DOM) fluorescence and $\mathrm{HO}$ and the photochemical oxygen demand of surface water DOM across the subtropical Atlantic Ocean. Limnol Oceanogr 46:632-643

Petchey OL, McPhearson PT, Casey TM, Morin PJ (1999) Environmental warming alters food-web structure and ecosystem function. Nature 402:69-72

Plag HP, Tsimplis MN (1999) Temporal variability of the seasonal sea-level cycle in the North Sea and Baltic Sea in relation to climate variability. Global Planet Change 20: 173-203

Puddu A, Zoppini A, Pettine M (2000) Dissolved organic matter and microbial food web interactions in the marine environment: the case of the Adriatic Sea. Int J Environ Pollut 13:473-494
Roeckner E, Arpe K, Bengtsson L, Cristoph M and 6 others (1996) The atmospheric general circulation model ECHAM-4: model description and simulation of presentday climate. MPI-Report 218, Max Plank Institute for Meteorology, Hamburg

Roeckner E, Bengtsson L, Feichter J, Lelieveld J, Rodhe H (1999) Transient climate change simulations with a coupled atmosphere-ocean GCM including the tropospheric sulfur cycle. J Clim 12:3004-3032

Ruardij P, Van Raaphorst W (1995) Benthic nutrient regeneration in the ERSEM ecosystem model of the North Sea. Neth J Sea Res 33:453-483

Sarmiento JL, Hughes TMC, Stouffer RJ, Manabe S (1998) Simulated response of the ocean carbon cycle to anthropogenic climate warming. Nature 393:245-249

Simas T, Nunes JP, Ferreira JG (2001) Effects of global climate change on coastal salt marshes. Ecol Model 139:1-15

Smodlaka N (1986) Primary production of the organic matter as an indicator of the eutrophication in the northern Adriatic Sea. Sci Total Environ 56:211-220

Solé RV, Manrubia SC, Benton M, Kauffman S, Bak P (1999) Criticality and scaling in evolutionary ecology. Trends Ecol Evol 14:156-160

Steele JH (1985) A comparison of terrestrial and marine ecological systems. Nature 313:355-358

Vichi M (2000) The influence of high-frequency surface forcing on productivity in the euphotic layer. In: Fischer J, Baretta J, Colijn F, Flemming NN (eds) Bio-ecological observations in operational oceanography. EuroGOOS Publication No. 15. Southampton Oceanography Centre, Southampton, p 29-30

Vichi M (2002) Predictability studies of coastal marine ecosystem behavior. $\mathrm{PhD}$ thesis, University of Oldenburg, available at http://docserver.bis.uni-oldenburg.de/ publikationen/dissertation/2002/vicpre02/vicpre02.html

Vichi M, Pinardi N, Zavatarelli M, Matteucci G, Marcaccio M, Bergamini MC, Frascari F (1998a) One-dimensional ecosystem model tests in the Po Prodelta Area (northern Adriatic Sea). Environ Model Software 13:471-481

Vichi M, Zavatarelli M, Pinardi N (1998b) Seasonal modulation of microbial-mediated carbon fluxes in the northern Adriatic Sea. Fish Oceanogr 7:182-190

Vichi M, Baretta JW, Ruardij P (2000) Non-linear response in complex ecosystem models: possible implications for the biological data assimilation. In: Robinson AR, Lermusiaux PFJ (eds) Workshop on the assimilation of biological data in coupled physical/ecosystem models, GLOBEC Special Contribution. GLOBEC International Project Office, Plymouth, UK, p E45-E47

Vichi M, Oddo P, Zavatarelli M, Coluccelli A, Coppini G, Celio M, Fonda Umani S, Pinardi N (2003) Calibration and validation of a one-dimensional complex marine biogeochemical fluxes model in different areas of the northern Adriatic shelf. Ann Geophys 21:413-436

Zavatarelli M, Bregant D, Raicich F, Russo A, Artegiani A (1998) Climatological biogeochemical characteristic of the Adriatic Sea. J Mar Syst 18:227-263

Zavatarelli M, Baretta JW, Baretta-Bekker JG, Pinardi N (2000) The dynamics of the Adriatic Sea ecosystem; an idealized model study. Deep Sea Res 47:937-970

Zavatarelli M, Pinardi N, Kourafalou VH, Maggiore A (2002) Diagnostic and prognostic model studies of the Adriatic Sea general circulation: seasonal variability. J Geophys Res 107(C1), 3004, doi:10.1029/2000JC000210, 2002

Submitted: February 17, 2002; Accepted: April 6, 2003

Proofs received from author(s): July 3, 2003 